\section{Enumeration of coliform bacteria and characterization of Escherichia coli isolated from Staff Club swimming pool in lle-lfe, Nigeria}

\author{
Tolutope O. Akeju, Kehinde O. Awojobi \\ Department of Microbiology, Obafemi \\ Awolowo University, Ile-Ife, Osun State, \\ Nigeria
}

\begin{abstract}
Water recreation, though increasing globally, is strongly associated with infectious diseases. Unexpectedly, artificial water recreation systems e.g. swimming pools account for $90 \%$ of these outbreaks. It is therefore essential that pool waters be regularly monitored for deviations from microbial water quality guidelines. To assess the sanitary quality of a club swimming pool in Ile-Ife, Nigeria, we used the multiple-tube fermentation technique to determine the most probable number (MPN) of coliform bacteria in $100 \mathrm{~mL}$ of pool water. MPN estimates ranged from 9 to 93 with geometric mean of 38. Escherichia coli was isolated from positive presumptive tubes, indicating recent fecal contamination. The isolate elicited similar biochemical reactions as reference $E$. coli (25922), except that it utilized sucrose and liquefied gelatin, which probably indicates potential pathogenicity. Also, the $E$. coli isolate was resistant to 13 antibiotics from 9 different classes. Finally, coliform counts and detection of $E$. coli clearly violates international guidelines. We recommend that pool operators increase water disinfection efficiency and educate the public on the need for improved swimmer hygiene to reduce the risk of recreational water illness transmission.
\end{abstract}

\section{Introduction}

The recreational use of water is growing worldwide mainly because of its beneficial impact to human health. ${ }^{1,2}$ In the United States alone, over 301 million swimming visits were made by persons aged 7 and above in 2009. ${ }^{3}$ However, body-contact water recreation has been strongly associated with infectious diseases and artificial water systems - e.g. swimming pools and spas - account for more than $90 \%$ of these disease outbreaks. ${ }^{4}$ Consequently, pool waters need to be monitored regularly for pathogenic microorganisms originating from fecal contamination or bather shedding e.g. Escherichia coli 0157, Campylobacter jejuni, Shigella spp, Cryptosporidium parvum and Rotaviruses. Non-fecal pathogens like Legionella pneumophila and Pseudomonas aeruginosa have also been documented to cause recreational water illnesses (RWIs). ${ }^{1}$

Over the years, the detection and isolation of pathogens from water have proved difficult and indicator organisms are used as surrogates. Coliform bacteria were initially used for formulating water quality standards due to their ease of enumeration via the multipletube fermentation (MTF) technique until recent discovery about total coliforms originating from dissimilar sources. ${ }^{5}$ While coliform genera like Escherichia and Klebsiella are mostly native inhabitants of the intestinal tract, others like Enterobacter and Citrobacter can originate from faecal, plant and soil materials. ${ }^{6,7}$ Alternatively, E. coli and Enterococcus spp. provides a more reliable indication of fecal pollution and have been included as key parameters in water quality guidelines in the European Union, Australia and the United States. ${ }^{7}$ Compared to beaches and rivers that rely on natural purification processes, the risk of disease transmission should be reduced in disinfected pool waters. Nonetheless, pool waters are highly vulnerable to swimmerinduced contamination and continuous disinfection may be unable to completely eliminate released pathogens before water ingestion. ${ }^{8}$ Research has shown that on average, adults swallow $16 \mathrm{~mL}$ of pool water per swimming event and children $37 \mathrm{~mL}$, almost twice as adults. ${ }^{9}$ The Centers for Disease Control and Prevention (CDC) substantiated this highexposure scenario when recent research revealed the presence of $E$. coli in 58\% of pool filter samples. ${ }^{10}$ To reduce the incidence of recreational water illnesses (RWIs), microbiological quality guidelines similar to those for drinking water should apply to swimming pools. Since brief exposures to water-borne pathogens can lead to diseases, the short-term monitoring of recreational water for deviations from microbial water quality standards is crucial to public health maintenance. ${ }^{2}$ But water quality regulations for swimming pools or spas are yet to exist in Nigeria and scientific investigations, though scant, have consistently indicated the non-compliance of pool waters to international standards. Hence, more studies are needed to generate additional information necessary for the development of swimming pool water quality standards. This study aimed at assessing the sanitary quality of a swimming pool using total coliforms as indicators and also by characterizing any isolated organism.
Correspondence: Tolutope Oluseyi Akeju, 22-6715 Hunterview Drive NW, Calgary, Alberta T2K 5C8, Canada.

Tel.: +1.234.706.595.1381.

E-mail: toppeeakeju@yahoo.com

Key words: Coliform; swimming pool; Escherichia coli.

Acknowledgements: The authors would like to thank the Department of Microbiology, Obafemi Awolowo University (OAU), Ile-lfe for infrastructural support and for granting access to the Staff Club swimming pool in Ile-Ife.

Contributions: TOA performed the experimental work, data analysis and interpretation. TOA also prepared the initial draft of the manuscript. KOA conceptualized the study, contributed to the experimental design, reviewed initial manuscript draft and approved of the final version to be published.

Conflict of interest: the authors declares no potential conflict of interest.

Received for publication: 28 April 2015.

Revision received: 20 September 2015.

Accepted for publication: 21 September 2015.

This work is licensed under a Creative Commons Attribution NonCommercial 3.0 License (CC BYNC 3.0).

(C)Copyright T.O. Akeju and K.O. Awojobi, 2015 Licensee PAGEPress, Italy

Microbiology Research 2015; 6:5972

doi:10.4081/mr.2015.5972

\section{Materials and Methods}

\section{Sampling procedures}

During a 35-day period from April to June 2009 , five water samples (one per week) were collected from Staff Club Swimming Pool located at the staff quarters of Obafemi Awolowo University, Ile-Ife, Nigeria. This pool is semipublic, with bathing access restricted to only registered staff members and their guests. Pool water sampling was conducted according to standard practices. ${ }^{2,8}$ To ensure sampling was representative of pool water quality, water was collected at a depth of $30 \mathrm{~cm}$, close to swimmers and well distanced from outlets. Sampling occurred during periods of high bathing load and varied with regards to daily and weekly collection time.

\section{Standard bacteriological analysis of pool water}

For a pool that is routinely disinfected, low coliform counts were expected and isolated organisms should provide a qualitative assess- 
ment of recent fecal contamination. To achieve this objective, the conventional MTF technique was used to determine the most probable number (MPN) of coliform bacteria present in 100 $\mathrm{mL}$ of pool water. This technique normally involves three steps as shown below (Figure 1).

\section{Presumptive test}

Differential medium for the isolation of coliforms was MacConkey broth Purple. Three broth tube series - the first series containing 3 double strength broth tubes and the remaining two series comprising 6 single strength broth tubes - were inoculated with $10 \mathrm{~mL}, 1$ $\mathrm{mL}$ and $0.1 \mathrm{~mL}$ of water (ratio 3:3:3) respectively. Tubes were incubated at $37^{\circ} \mathrm{C}$ and observed at 24 and 48 hours. Presumptive test is positive for coliforms if acid and gas are produced in Durham tubes.

\section{Confirmed test}

To eliminate false-positives from non-coliform organisms, eosin methylene blue (EMB) agar plates were inoculated with a loopful from each positive presumptive broth tube by streaking across the agar surface. Plates were incubated for $24 \mathrm{~h}$ at $37^{\circ} \mathrm{C}$.

\section{Completed test}

Finally, nutrient agar slants and MacConkey broth tubes were inoculated with distinct colonies picked from cultured isolates on EMB agar plates. After incubation for $24 \mathrm{~h}$ at $37^{\circ} \mathrm{C}$, broth cultures were observed for acid and gas production and cultured isolates on agar slants were gram stained using standard technique. ${ }^{11}$

\section{Biochemical characterization}

Besides IMViC which stands for indole, methyl red, Voges-Proskauer and citrate tests, four other biochemical tests, i.e. catalase, gelatin liquefaction, starch hydrolysis and sugar fermentation were performed to confirm the identity of test isolate according to standard methods. ${ }^{11,12}$

\section{Antibiotic susceptibility test}

The Kirby-Bauer disk diffusion technique was used to measure the susceptibility of the isolate to 13 commonly used antibiotics in Nigeria. Test was performed using Mueller-Hinton agar (Oxoid Code CM0337) and two types of antibiotic multidisc (Gram positive; MICRORING/DT-NEG and Gram negative; MICRORING/DT-POS). Names, codes and concentrations of tested antibiotics are shown in Table 1.

\section{Procedure}

Smeared inoculum from 18-24 h nutrient broth culture of isolated organism was spread evenly on the agar surface with a sterile swab stick. Using sterile forceps, antibiotic multi-discs were placed at the center of inoculated media. Plates were inverted and incubated at $37^{\circ} \mathrm{C}$ for $24 \mathrm{~h}$. Thereafter, zones of inhibition around the discs were observed, their diameters measured and classified as resistant (R), susceptible (S) or intermediate (I) according to interpretive criteria defined by the Clinical and Laboratory Standards Institute (CLSI). ${ }^{13}$

\section{Statistical analysis}

MPN of coliform bacteria per $100 \mathrm{~mL}$ of original water sample was determined from a standard 3-tube statistical table. ${ }^{5}$ Geometric mean (Geomean), standard deviation (SD) and coefficient of variation (CV \%) were calculated using predefined functions in MS Excel. Equation for the geometric mean is stated below:

$$
\text { Geomean=antilog }\left(\frac{\sum_{\mathrm{i}=1}^{\mathrm{n}} \log \mathrm{x}_{\mathrm{i}}}{\mathrm{n}}\right)
$$

Where $x_{i}=$ individual MPN values and $n=5$.

\section{Results}

Change in broth color from purple to yellow and presence of gas in Durham tubes indicated the presence of coliforms in positive presumptive tubes. On EMB agar, confirmed test for coliform bacteria showed the appearance of $E$. coli alonedistinguished by the typical greenish metallic sheen. In the completed tests, acid and gas were observed in broth tubes and gram stain revealed red, non-spore forming rods, indicating the bacterial isolate is gram-negative. The MPN of coliform bacteria, as presented in Table 2 , ranged from 9 to 93. Geomean, SD, and CV\% of MPN values were $38,2.37$ and $6.3 \%$ respectively. The $95 \%$ confidence limits (Geomean $\pm 2 \mathrm{SD}$ ) were 6.7 (lower limit) and 211.6 (upper limit).

$E$. coli was isolated from each of the five water samples, maintained as stock cultures on nutrient agar slants, and one of these isolates was selected for further qualitative biochemical analyses. In Table 3, comparisons of biochemical reactions for the reference $E$. coli strain (ATCC$25922)^{14}$ and the $E$. coli isolate showed differences in gelatin liquefaction and sucrose fermentation reactions. Antibiotic susceptibility tests for the $E$. coli isolate revealed resistance to all tested antibiotics (Table 1).

\section{Discussion}

\section{Validity of laboratory test proce- dures}

Low co-efficient of variation (6.3\%) coupled with the fact that range of MPN estimates (993) was contained within $95 \%$ confidence limits (6.7-211.6) of the geometric mean validates intra-laboratory test procedures. However, the 95\% confidence intervals of the individual coliform counts (Table 2) and the geometric mean are wide enough to reveal the inherent low precision of MPN estimates. Ever since, researchers have duly recommended increasing the number of tube replicates and samples to overcome this imprecision and compared to plate counts, the MPN can provide more accurate estimates when bacteria counts are low. ${ }^{15}$

Table 1. Antibiotic susceptibility profile of $E$. coli isolated from Staff Club swimming pool.

\begin{tabular}{|c|c|c|c|c|}
\hline $\begin{array}{l}\text { Antibiotic } \\
\text { Name }\end{array}$ & Code & Concentration, $\mu \mathrm{g}$ & $\begin{array}{c}\text { Inhibition } \\
\text { diameter, mm }\end{array}$ & Interpretation \\
\hline
\end{tabular}

Gram-Positive

$\begin{array}{lcccc}\text { Streptomycin } & \text { STR } & 25 & 9.0 & \text { R } \\ \text { Tetracycline } & \text { TET } & 25 & 0 & \text { R } \\ \text { Colistin } & \text { COL } & 25 & 0 & \text { R } \\ \text { Gentamycin } & \text { GEN } & 10 & 7.5 & \text { R } \\ \text { Nalixidic acid } & \text { NAL } & 30 & 0 & \text { R } \\ \text { Ampicillin } & \text { AMP } & 25 & 0 & \text { R } \\ \text { Nitrofurantoin } & \text { NIT } & 200 & 0 & \text { R } \\ \text { Cotrimoxazole } & \text { COT } & 25 & 0 & \text { R }\end{array}$

\begin{tabular}{llccl} 
Gram-Negative & & & \\
Streptomycin & STR & 10 & 8.5 & $\mathrm{R}$ \\
Erythromycin & ERY & 5 & 0 & $\mathrm{R}$ \\
Penicillin & PEN & 11 & 0 & $\mathrm{R}$ \\
Tetracycline & TET & 10 & 0 & $\mathrm{R}$ \\
Gentamycin & GEN & 10 & 8.0 & $\mathrm{R}$ \\
Cloxacillin & CXC & 10 & 0 & $\mathrm{R}$ \\
Chloramphenicol & CHL & 10 & 0 & $\mathrm{R}$ \\
Ampicillin & AMP & 10 & 0 & $\mathrm{R}$ \\
\hline
\end{tabular}

$\mathrm{R}$, resistant. 


\section{Are total coliforms suitable indica-} tors of pool water quality?

Recently, inclusion of total coliforms in compliance testing has been strongly debated due to their heterogeneous origins. ${ }^{6,7}$ Even the World Health Organization (WHO) ${ }^{2}$ excluded total coliforms from among suitable microbial parameters in the guidelines for safe recreational water. Nevertheless, studies have repeatedly shown that even true fecal indicators are unlikely to correlate with pathogen densities in water at low pollution levels. ${ }^{16}$ Additionally, densities of fecal coliforms and fecal streptococci in pool waters are usually low, making them unsuitable indicators. ${ }^{17}$ But total coliforms are present in sufficient densities, sensitive to chlorination and therefore reliable for assessing the efficiency of sanitary processes such as the disinfection of swimming pool waters. ${ }^{6,18}$

\section{Assessment of estimated most probable number of coliform bac- teria in Staff Club Swimming Pool}

Apart from WHO guidelines ${ }^{2}$ which state that thermo-tolerant coliforms or E. coli should be below 1/100 mL, several national organizations have bacteriological standards for pool waters that are more or less similar. According to German (DIN 19643/1984), British (BSI PAS 39:2003) and Greek (443/B/1974) regulations, total coliform counts should not exceed 0,10 and 14 per $100 \mathrm{~mL}$ and $E$. coli should be totally absent in $100 \mathrm{~mL}$ of pool water. ${ }^{19}$ Therefore, when assessed in the light of aforementioned regulations, the coliform bacteria counts estimated in this study were clearly above recommended limits and the bacteriological quality of this pool can be deemed unacceptable.

\section{Biochemical characterization of $E$. coli isolate}

Here, we discuss the significance and implications of observed differences in the biochemical profiles of $E$. coli and reference $E$. coli (ATCC-25922). The isolated $E$. coli can be identified as biotype I based on IMViC reaction pattern $(++--) .{ }^{20}$ In addition, knowing that most wild-type strains of $E$. coli are unable to produce -amylase for starch hydrolysis ${ }^{21}$ and that only $\leq 10 \%$ of commensal and pathogenic E. coli strains can ferment inositol ${ }^{22}$ can help explain the negative reactions obtained for starch and inositol respectively.

Most industrial E. coli strains are unable to liquefy gelatin and gelatinase is a virulence factor moderately expressed in pathogenic $E$. coli. For example, one study in South Africa reported gelatinase production in $60 \%$ of verotoxic $E$. coli isolates from water and wastewater samples..$^{23}$ In addition, while $19.4 \%$ of $E$. coli isolates from urinary tract infection patients produced gelatinase, none from healthy persons was gelatinase positive. ${ }^{24}$ Therefore, the gelatin liquefaction elicited by this $E$. coli isolate may indicate pathogenicity. Sucrose-utilizing $E$. coli strains are mostly pathogenic, and E. coli W (ATCC-9637) is the only sucrose positive commensal/laboratory strain. ${ }^{25}$ Because most pathogenic E. coli strains belong the biotype I group, the positive reaction for sucrose may infer pathogenicity but serological and molecular testing would be needed for confirmation. ${ }^{20,22}$

\section{Antibiotic resistance}

The $E$. coli isolate was resistant to all 13 antibiotics, which is unsurprising because of the rise of antimicrobial resistance. The $\mathrm{WHO}^{26}$ noted that though antimicrobial resist- ance is a normal evolutionary process, the widespread and indiscriminate use of antibiotics in human and veterinary medicine have escalated this process in recent decades. ${ }^{26}$ In the US for instance, resistance of $E$. coli isolates to $\geq 3$ classes of antibiotics (i.e. multidrug resistance) increased from $7 \%$ in the 1950 s to $64 \%$ in the 2000 s. $^{27}$

$E$. coli acquires resistance genes easily and has recently shown resistance, not just to older, commonly used antibiotics, but also to fluoroquinolones and third generation cephalosporins. ${ }^{26,27}$ Multi-drug resistance (MDR) in $E$. coli is probably much worse in developing countries ${ }^{28}$ and in Nigeria for example, resistance of $E$. coli isolates from students to tetracycline, ampicillin, chloramphenicol and streptomycin increased from 9-

Table 2. The most probable number (MPN) of coliform bacteria in Staff Club swimming pool, OAU, Ile-Ife (Nigeria).

\begin{tabular}{|c|c|c|c|c|c|}
\hline $\begin{array}{l}\text { Sample } \\
\text { number }\end{array}$ & $\begin{array}{l}\text { Water Tota } \\
\text { volume, } \mathrm{mL}\end{array}$ & $\begin{array}{l}\text { I number of } \\
\text { tubes }\end{array}$ & $\begin{array}{c}\text { Number of } \\
\text { positive tubes }\end{array}$ & $\begin{array}{l}\text { MPN per } \\
100 \mathrm{~mL}\end{array}$ & $\begin{array}{c}95 \% \\
\text { confidence } \\
\text { interval }\end{array}$ \\
\hline 1 & $\begin{array}{l}10 \\
1.0 \\
0.1\end{array}$ & $\begin{array}{l}3 \\
3 \\
3\end{array}$ & $\begin{array}{l}3 \\
0 \\
1\end{array}$ & 39 & $7-130$ \\
\hline 2 & $\begin{array}{l}10 \\
1.0 \\
0.1 \\
\end{array}$ & $\begin{array}{l}3 \\
3 \\
3 \\
\end{array}$ & $\begin{array}{l}3 \\
1 \\
0\end{array}$ & 48 & $7-210$ \\
\hline 3 & $\begin{array}{l}10 \\
1.0 \\
0.1\end{array}$ & $\begin{array}{l}3 \\
3 \\
3\end{array}$ & $\begin{array}{l}3 \\
2 \\
0\end{array}$ & 93 & $15-380$ \\
\hline 4 & $\begin{array}{l}10 \\
1.0 \\
0.1\end{array}$ & $\begin{array}{l}3 \\
3 \\
3 \\
\end{array}$ & $\begin{array}{l}2 \\
0 \\
0\end{array}$ & 9 & $1-36$ \\
\hline 5 & $\begin{array}{l}10 \\
1.0 \\
0.1\end{array}$ & $\begin{array}{l}3 \\
3 \\
3\end{array}$ & $\begin{array}{l}3 \\
1 \\
0\end{array}$ & 48 & $7-210$ \\
\hline
\end{tabular}

Table 3. Biochemical characteristics of $E$. coli isolated from Staff Club swimming pool, OAU, Ile-Ife (Nigeria).

Test Related E. colt Reaction Rerence E. coli (ATrCC-25922)

\begin{tabular}{llll} 
Indole & + & + \\
Methyl red & + & + \\
\hline Voges-Proskauer & - & - \\
Citrate & - & - \\
\hline Catalase & + & + \\
Starch hydrolysis & - & - \\
\hline Gelatin liquefaction & + & - \\
Mannitol & + & + \\
\hline Glucose & + & + \\
Sucrose & + & - \\
\hline Lactose & + & + \\
Inositol & - & -
\end{tabular}

ATCC, American Type Culture Collection; +, positive reaction; - , negative reaction. 


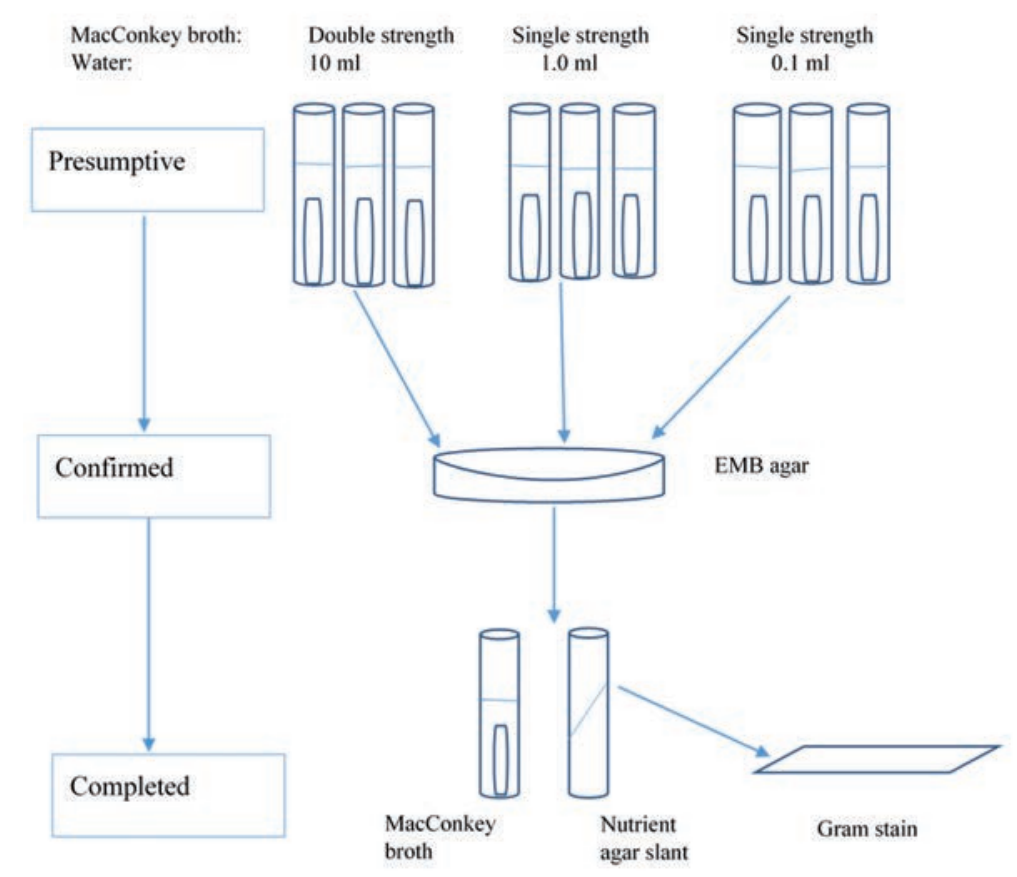

Figure 1. A simple illustration of the multiple-tube fermentation technique.

$35 \%$ in 1986 to $56-100 \%$ in $1998 .^{29}$

Since the $E$. coli isolated in this study is most probably derived from swimmers, human origin is presumed and MDR in human isolates is usually high. Consider one study on the susceptibility of $128 \mathrm{E}$. coli isolates to 13 antibiotics. E. coli isolates derived from humans were resistant to 2-13 antibiotics with mean resistance index of 0.67 , four times greater than resistance index (0.17) for animal isolates which were resistant to just 1-6 antibiotics. $^{30}$ In contrast, another study revealed higher antibiotic resistance in $E$. coli isolates from food animals. Specifically, 59.1\% of $E$. coli isolates from cattle, $53.7 \%$ from pigs and $55.1 \%$ from chicken exhibited MDR, compared to just $19.5 \%$ isolates from humans. Also, from the 796 pan-susceptible $E$. coli isolates, $80 \%$ were from humans, $8.7 \%$ from cattle, $7.5 \%$ from pigs and $3.9 \%$ from chickens. ${ }^{27}$ Perhaps, these two findings do not contrast so sharply. Indications have recently emerged that MDR $E$. coli strains can be transferred to humans through the food chain. The consumption of animal meat - particularly poultry where antibiotics are frequently used in feed - is the most likely source of multi-resistant $E$. coli in humans. $^{28}$

\section{Conclusions}

The unacceptable bacteriological pool water quality in this study indicates an increased risk for the transmission of RWIs. Besides enforcing adequate disinfection levels and compliance to microbial standards, pool operators must educate swimmers on the need for improved hygiene practices to prevent RWIs. For example, pre-swim showers, regular bathroom breaks, and not swimming during a gastro-enteric illness can significantly reduce the amount of urine, sweat and fecal material introduced into pool waters. ${ }^{10}$ We do accept that pool water quality assessments using only total coliforms and $E$. coli may be inadequate. For robust assessments, we recommend monitoring for chemical parameters and non-fecal bacteria e.g. Legionella and $P$. aeruginosa. ${ }^{2}$ High MDR in isolated $E$. coli highlights the growing threat of antibiotic resistance. Since no new class of antibiotics have been discovered since the $1980 \mathrm{~s},{ }^{26}$ public health efforts must be geared towards curbing the spread of antibiotic resistance, while the search for novel antimicrobials continue.

\section{References}

1. Pond K. Water recreation and disease. Plausibility of associated infections: acute effects, sequelae and mortality. 1st ed. London, UK: IWA Publishing on behalf of the World Health Organization; 2005. Available from: http://www.who.int/water_sanitation_heal th/bathing/recreadis.pdf
2. World Health Organization. Guidelines for safe recreational water. Volume 2, Swimming pools and similar environments. Geneva: World Health Organization; 2006.

3. US Census Bureau. Arts, recreation and travel. The statistical abstract of the United States [Internet]. 131th ed. US Census Bureau; 2012. pp. 768-9.

4. Doménech-Sánchez A, Olea F, Berrocal C. Infections related to recreational waters. Enferm Infecc Microbiol Clin 2008;26:32-7.

5. World Health Organisation. Guidelines for drinking-water quality. Volume 3 Surveillance and control of community supplies. 2nd ed. Geneva: World Health Organization; 1997.

6. Ashbolt NJ, Grabow WOK, Snozzi M. Indicators of microbial water quality. In: Fewtrell L, Bartram J, eds. Water quality: guidelines, standards and health. London, UK: IWA Publishing on behalf of the World Health Organization; 2001. pp 289-307.

7. Stevens M, Ashbolt N, Cunliffe D. Review of coliforms as microbial indicators of drinking water quality. Canberra, Australia; 2003. Available from: https://www.nhmrc.gov.au/files_nhmrc/p ublications/attachments/eh32.pdf

8. DeHaan W, Johanningsmeier JS. Bacteriological analysis of pool water. Swimming pool pest management: A training manual for commercial pesticide applicators and swimming pool operators category 5A. Michigan: Kent County Health Department/MSU Pesticide Education Program; 1997. pp. 33-5. Available from: http://www.ipm.msu.edu/pesticide_education_safety/training_manuals/swimming_pool_pest_management

9. Dufour A, Evans 0, Behymer T, Cantu R. Water ingestion during swimming activities in a pool: a pilot study. J Water Heal 2006;4:425-30.

10. Centres for Disease Control and Prevention. Microbes in pool filter backwash as evidence of the need for improved swimmer hygiene. Morbidity and Mortality Weekly Report. Metro-Atlanta, Georgia; 2013. Available from: http://www.ncbi.nlm. nih.gov/pubmed/23677044

11. Aneja KR. Experiments in microbiology, plant pathology and biotechnology. Reprint. New Delhi: New Age International; 2003.

12. Cheesbrough M. District laboratory practices in tropical countries, part 2. Revised. Cambridge: Cambridge University Press; 2006.

13. Clinical and Laboratory Standards Institute. Performance standards for antimicrobial susceptibility testing; Seventeenth informational supplement. Pennsylvania, USA: Clinical and 
Laboratory Standards Institute; 2007. pp 32-6. Available from: www.microbiolabbg.com/CLSI.pdf

14. Siegrist J. Differentiation of Escherichia coli from coliforms. AnalytiX. St. Louis: Sigma-Aldrich; 2011.

15. Sutton $S$. The most probable number method and its uses in enumeration, qualification, and validation. J Valid Technol 2010;16:35-8.

16. Payment P, Locas A. Pathogens in water: value and limits of correlation with microbial indicators. Ground Water 2011;49:4 11.

17. Seyfried PL. Bacterial indicators to estimate the health hazards associated with the use of swimming pools. Environ Toxicol Water Qual 1989;4:317-27.

18. Nikaeen M, Hatamzadeh M, Vahid Dastjerdi, M Hassanzadeh A. Predictive indicators of the safety of swimming pool waters. Water Sci Technol 2009;60:3101-7.

19. Papadopoulou C, Economou V, Sakkas H, et al. Microbiological quality of indoor and outdoor swimming pools in Greece: investigation of the antibiotic resistance of the bacterial isolates. Int J Hyg Environ Health 2008;211:385-97.
20. Odonkor ST, Ampofo JK. Escherichia coli as an indicator of bacteriological quality of water: an overview. Microbiol Res (Pavia) 2013;4:e2.

21. Rosales-Colunga LM, Martínez-Antonio A. Engineering Escherichia coli K12 MG1655 to use starch. Microb Cell Fact 2014;13:74.

22. Leclercq A, Lambert B, Pierard D, Mahillon J. Particular biochemical profiles for enterohemorrhagic Escherichia coli 0157:H7 isolates on the ID 32E system particular biochemical profiles for enterohemorrhagic Escherichia coli 0157:H7 isolates on the ID $32 \mathrm{E}$ system. J Clin Microbiol 2001;39:1161-4.

23. Doughari HJ, Ndakidemi PA, Human IS, Benade S. Virulence factors and antibiotic susceptibility among verotoxic non 0157:H7 Escherichia coli isolates obtained from water and wastewater samples in Cape Town, South Africa. African J Biotechnol 2011;10:14160-8.

24. Shruthi N, Kumar R, Kumar R. Phenotypic study of virulence factors in Escherichia Coli isolated from antenatal cases, catheterized patients, and faecal flora. J Clin Diagnostic Res 2012;6:1699-703.

25. Sabri S, Nielsen LK, Vickers CE. Molecular control of sucrose utilization in Escherichia coli W, an efficient sucroseutilizing strain. Appl Environ Microbiol 2013;79:478-87.

26. World Health Organization. Antimicrobial resistance. Global report on surveillance [Internet]. World Health Organization; 2014. Available from: http://apps.who. int/iris/bitstream/10665/112642/1/9789241 564748_eng.pdf

27. Tadesse DA, Zhao S, Tong E, et al. Antimicrobial drug resistance in Escherichia coli from humans and food animals, United States, 1950-2002. Emerg Infect Dis 2012;18:741-9.

28. Collignon P. Resistant Escherichia coli we are what we eat. Clin Infect Dis 2009;49:202-4.

29. Okeke IN, Fayinka ST, Lamikanra A. Antibiotic resistance in Escherichia coli from Nigerian students, 1986-1998. Emerg Infect Dis 2000;6:393-6.

30. Vantarakis A, Venieri D, Komninou G, Papapetropoulou M. Differentiation of faecal Escherichia coli from humans and animals by multiple antibiotic resistance analysis. Lett Appl Microbiol 2006;42:71-7. 